\title{
BRÁS CUBAS, MARCELA E CRÔNICAS: DESEJO E INTERESSE
}

\section{ROBERTA DA COSTA DE SOUSA}

Universidade Federal do Rio de Janeiro

Rio de Janeiro, Rio de Janeiro, Brasil

Resumo: Análise da sequência de capítulos da obra Memórias póstumas de Brás Cubas, de Machado de Assis, acerca do relacionamento de Brás Cubas e Marcela. O encantamento do protagonista contrasta com o interesse apenas de proveito material por parte de Marcela. Ilusão, pragmatismo, decepção, interesse. O narrador defunto machadiano oscila entre o distanciamento do relato e a recuperação do sentimento vivido. Além disso, a construção da personalidade da personagem feminina do romance se assemelha a comentários a respeito do comportamento de mulheres do século XIX presentes nas crônicas de Machado de Assis, publicadas na Gazeta de Notícias. Romance e crônicas confirmam o ceticismo machadiano também quanto a relacionamentos entre homens e mulheres.

Palavras-chave: Machado de Assis; Brás Cubas; crônica; personagens femininas.

\section{BRÁS CUBAS, MARCELA AND CHRONICLES: DESIRE AND INTEREST}

\begin{abstract}
Analysis of the sequence of the chapters in Machado de Assis's novel, Memórias póstumas de Brás Cubas, with a focus on the relationship between Brás Cubas and Marcela. The protagonist's passion is in opposition to Marcela's material interest. Illusion, pragmatism, deception, interest. The deceased Machadian narrator swings between the distance produced by giving his account and the quest for recovering the feelings he experienced. Furthermore, the construction of the novel's feminine character's personality is similar to commentary regarding the behavior of nineteenth-century women featured in Machado de Assis's chronicles published by Gazeta de Notícias. The novel and the chronicles confirm Machado de Assis's skepticism even concerning relationships between men and women.
\end{abstract}

Keywords: Machado de Assis; Brás Cubas; chronicle; feminine characters. 
$\mathrm{Q}$ uando Machado de Assis iniciou a colaboração como cronista na Gazeta de Notícias, em 1892, já desenvolvera o estilo que o consagrou como grande escritor da literatura brasileira, pois dois romances estavam publicados: Memórias póstumas de Brás Cubas e Quincas Borba. Ambos constam como integrantes daquela que seria considerada a "fase madura" da obra machadiana, que ainda conta com outros romances posteriores às crônicas da série "A Semana": Dom Casmurro; Esaú e Jacó; e Memorial de Aires. A "dialética da proximidade e da distância do olhar" (PETRAGLIA; LIMA; MELLO, 2018, p. 10) presente nas análises da sociedade brasileira das crônicas revelava os hábitos e costumes locais, por meio do olhar crítico do escritor que, embora pertencente à localidade, conseguia alhear-se o suficiente, a fim de vivenciar o cotidiano com estranhamento. Essa complexa e contraditória relação entre proximidade e distanciamento, fundamental à capacidade crítica, também se vislumbra no modo de relatar do narrador-personagem Brás Cubas, que, morto, redige as próprias memórias.

O recurso ficcional irrealista e inverossímil do defunto autor em Memórias póstumas de Brás Cubas permite desnudar o ego do narrador, que, já entre os vermes, não se preocupa mais com a imagem a zelar. Conforme Bosi (2006, p. 310), "o que avulta no romance é uma dialética de memória e distanciamento cético do narrador em relação a si próprio". Estrategicamente póstumas, as lembranças permitem ao narrador extremamente crítico expor a coisificação social. Isso se inicia no "duplo jogo de presença e distanciamento do eu" (BOSI, 2006, p. 281), pela necessidade de presença física aos acontecimentos da condição de testemunha ocular de alguém não mais presente fisicamente, o que potencializa o gesto reflexivo entre a matéria lembrada e a respectiva interpretação.

A relação entre o Brás Cubas narrador e o Brás Cubas narrado configura-se na alternância da narração, que, por ora, se pauta pela visão do narrador defunto no momento da narração e, por vezes, orienta-se pela tentativa de recuperar as sensações do momento da vivência. $\mathrm{O}$ narrador defunto contempla o passado e faz o relato com análise baseada na experiência de vida completa, o que permite um olhar totalmente diverso do momento em que vivenciou a situação com análise distanciada repleta de ironia e sarcasmo.

Essa dialética de visões durante a narrativa permeia os relacionamentos íntimos com mulheres ao longo da vida. A relação entre Brás Cubas e Marcela principia com o típico encantamento inicial por parte do enamorado, que se conclui com grave decepção. Esta promove a modificação 
da visão a respeito da personalidade dela, enquanto ainda era vivo. Contudo, ao contar o início do caso, o narrador consegue transmitir a idealização ainda não abalada por acontecimentos futuros na ordem cronológica do relato, mas já passados na vida do narrador, que deflagram outro tipo de relação com Marcela. Ao longo da sequência, o narrador se dispõe a contar o "primeiro cativeiro pessoal" (ASSIS, 1997, p. 30), como assim definiu o amor ao fim do capítulo 13. Sua primeira paixão foi por Marcela, espécie de prostituta de luxo. No entanto, em nenhuma passagem, Brás Cubas a define dessa maneira ou por qualquer outra designação pejorativa. Ao contrário, a primeira descrição se transforma em tentativa de categorização sem êxito, pois ele interrompe a narrativa justamente para não ter de defini-la: "De todas porém a que me cativou logo foi uma... uma... não sei se diga; este livro é casto, ao menos na intenção; na intenção é castíssimo. Mas vá lá; ou se há de dizer tudo ou nada" (ASSIS, 1997, p. 30).

Apesar da advertência sobre a metodologia da escrita, o narrador não vai dizer tudo: "A que me cativou foi uma dama espanhola, Marcela, a 'linda Marcela', como lhe chamavam os rapazes do tempo" (ASSIS, 1997, p. 30). O mais próximo que chega da nomenclatura adequada ao comportamento da moça é "amiga de dinheiro e de rapazes". Admite que a atração por ela se deve a algo que não encontrara nas "mulheres puras" (ASSIS, 1997, p. 30). Dessa forma, demonstra certa benevolência com a jovem, o que indica que os fatos narrados são influenciados pelo tipo de relação existente entre os personagens, ou seja, o narrador não é isento e, mesmo morto, não prevalece a imparcialidade na narrativa.

No capítulo 15, a lembrança de Marcela torna-o até gentil com o leitor, cujo tratamento, ao longo do romance, costuma ser irônico e debochado. Agora, ante a reminiscência do encanto passional, imprime até mesmo um tom confessional e certa cumplicidade, pois, se o leitor já viveu um amor na juventude, o narrador sabe que será compreendido por ele. Ao contrário de outros momentos em que duvida da capacidade do leitor (ou leitora) habituado a folhetins de chegar a alguma conclusão por si próprio, nesse caso basta a sabedoria oriunda da experiência. Após comparar a "primeira comoção da minha juventude" ao efeito do primeiro sol na criação bíblica, afirma: "pois foi a mesma cousa, leitor amigo, e se alguma vez contaste dezoito anos, deves lembrar-te que foi assim mesmo" (ASSIS, 1997, p. 32).

Em seguida, estabelece comparação mais racional que emocional a partir da política romana. $O$ narrador defunto assiste à situação distanciadamente, mas ainda apresenta dificuldade de lidar com o indefinível: "teve duas fases a nossa paixão, ou ligação, ou qualquer outro 
nome, que eu de nomes não curo" (ASSIS, 1997, p. 32). A República romana era governada por dois cônsules, por isso, quando Brás Cubas dividiu o amor de Marcela com Xavier, outro amante da personagem, classificou o período como "fase consular". Quando Xavier sai de cena, Cubas concentra todos os poderes e, então, decorre a "fase imperial ou cesariana".

Entretanto, tal honra exige sacrifícios financeiros cada vez maiores do protagonista, que saca da herança do pai e recorre a sucessivos empréstimos, para oferecer joias a Marcela. Ao recebê-las, ela protestava, até demonstrava relutância, mas aceitava o presente com nítida felicidade. Tudo não passava de grande encenação teatral. Em uma delas, Brás Cubas descobre que a cruz que ela dizia ser presente do pai era, na verdade, de um amante anterior.

Em nenhum fragmento, o narrador acusa Marcela de dissimulada ou interesseira. As ações narradas, porém, levam o leitor a tal conclusão, construindo a personalidade da personagem protegida pela narração de Brás Cubas, que parece recuperar a vivência do sentimento de outrora à medida que relata os fatos. "Marcela teve primeiro um silêncio indignado; depois fez um gesto magnífico: tentou atirar o colar à rua. Eu retive-lhe o braço; pedilhe muito que não me fizesse tal desfeita, que ficasse com a joia. Sorriu e ficou" (ASSIS, 1997, p. 35).

A dissimulação consiste em característica constante das personagens femininas de Machado de Assis. Ainda em Memórias póstumas de Brás Cubas, ressalta a capacidade de Virgília em disfarçar ao marido o caso extraconjugal com o protagonista. Todavia, a representante máxima é Capitu, de Dom Casmurro, a de "olhos de cigana oblíqua e dissimulada" (ASSIS, 1994, p. 53).

No mesmo capítulo 15 , há também a menção a outra dificuldade de definição expressa claramente pelo narrador, que confessa a falta de exatidão, pois o passado, ao ser revivido, é reinterpretado. Isso conduz ao relativismo histórico: não se pode ter acesso aos fatos como eles realmente foram. Macro ou micro, a História consiste sempre em uma interpretação. Brás Cubas não conseguia classificar a expressão facial de Marcela na época por não a compreender. Contudo, o ato de narrar lhe permite outra visão do momento e, enfim, estabelece comparação paradoxal. Marcela reúne simultaneamente os clássicos estereótipos femininos de anjo e demônio: "mas agora, relembrando o caso, penso que era um riso misto, como devia ter a criatura que nascesse, por exemplo, de uma bruxa de Shakespeare com um Serafim de Klopstock. Não sei se me explico" (ASSIS, 1997, p. 33).

O capítulo 16 se introduz com reflexão imoral. "Marcela morria de amores pelo Xavier. Não morria, vivia. Viver não é a mesma cousa que 
morrer; assim o afirmam todos os joalheiros desse mundo [...]" (ASSIS, 1997, p. 35). O início do trecho favorece a bonita leitura de que é preciso viver para amar e não morrer de amor ou por amor, como exaltava a literatura feminina tradicional. Esse tipo de reflexão também se encontra em outra obra machadiana, Esaú e Jacó: "O amor, que é a primeira das artes da paz, pode-se dizer que é um duelo, não de morte, mas de vida [...]" (ASSIS, 2003, p. 28).

No entanto, ao citar os joalheiros como fonte, revela o teor materialista da declaração. Afinal, morto não compra joias, nem as recebe, não usufrui das vantagens materiais que o amor pode ofertar. Quem ama deseja agradar ao amado e concede presentes na tentativa de demonstrar o afeto, ou seja, expressar o inexprimível em objetos, a fim de garantir a permanência do amado: sentimentos materializáveis. A questão é que Brás Cubas sabia o nível de vida que Marcela levava, os presentes que os outros amantes lhe ofereciam e não pretendia ser inferior a eles para não a perder ao dedicar-lhe regalos mais simples. Total consciência de que o sentimento em si não garante a longevidade do relacionamento, mas sim o conforto e o estilo de vida de alto padrão propiciados. Dessa forma, parece justificar os atos que terminarão por obrigá-lo a viajar a Portugal, protegendo Marcela do julgamento do leitor: "[...] a mais bela testa do mundo não fica menos bela, se a cingir um diadema de pedras finas; nem menos bela, nem menos amada" (ASSIS, 1997, p. 35).

A transição para o posterior capítulo traz interessante jogo ao leitor, pois a última frase é interrompida por reticências - "Marcela amou-me..." (ASSIS, 1997, p. 36) - e só completada no capítulo seguinte: "...Marcela amou-me durante quinze meses e onze contos de réis; nada menos" (ASSIS, 1997, p. 36). Essa corresponde à conclusão do Brás Cubas narrador, pois o narrado ainda não se convenceu do lado interesseiro de Marcela. À medida que a narrativa avança e os fatos narrados permitem outra visão do relacionamento, a razão gradativamente toma conta e engendra o distanciamento em relação à narração.

Ante a exigência paterna de estudar em Coimbra e a recusa de Marcela em acompanhá-lo na viagem, Cubas finalmente experimenta o desespero da paixão e, somente então, cai em si, adquirindo visão racional da situação. Bem diferente de Marcela, cujas experiências amorosas lhe proporcionaram frieza e olhar mais realista sobre o amor. A demora de Brás Cubas em se conscientizar do pragmatismo de Marcela contrasta com a praticidade da própria, a qual sabe, desde o princípio da relação, que todo relacionamento dispõe de início, meio e fim, não é eterno, nem único: "Amei a outro; que importa, se acabou? Um dia, quando nos separarmos..." (ASSIS, 1997, p. 34). 
Ela apresenta plena consciência de que Cubas era apenas mais um homem de passagem em sua vida. Simplesmente aproveitava o que ele podia lhe oferecer, sem ilusões.

Postura distinta das reações de Brás Cubas diante do fim dos relacionamentos. Com Marcela, deixa-se dominar pelo desespero: "fui eu que me atirei aos pés dela, contrito e súplice; beijei-lhos [...], pedi-lhe com lágrimas que me não desamparasse [...]" (ASSIS, 1997, p. 37). Atitude distinta do final da relação com Virgília, em outro momento, de maior maturidade do personagem, após passar por todas as Marcelas da vida. Há ainda a alfinetada nas exacerbações de emoções melodramáticas típicas do Romantismo, com mais uma referência direta ao leitor: "Não se irrite o leitor com esta confissão. Eu bem sei que, para titilar-lhe os nervos da fantasia, devia padecer um grande desespero, derramar algumas lágrimas, e não almoçar. Seria romanesco; mas não seria biográfico" (ASSIS, 1997, p. 163). A ruptura de expectativa quanto ao sofrimento tipicamente romântico inclui não perder a fome, seguir a vida naturalmente, como se a finitude constituísse fato esperado para aquele que mantém caso extraconjugal: "A realidade pura é que eu almocei, como nos demais dias [...]" (ASSIS, 1997, p. 163).

Não obstante, Brás Cubas também privilegia o material em sua paixão, quando utiliza como último recurso para não perder Marcela presenteá-la com um pente de diamantes. Diante do desespero, revela-se o principal teor do relacionamento e o narrador reconhece esse aspecto, embora ainda se deixe levar pela ingenuidade, ao repetir ao longo dos capítulos a crença no amor de Marcela. É a persistência na defesa da personagem que garante a proteção às conclusões maliciosas do leitor. "Certo é que os diamantes corrompiam-me um pouco a felicidade; mas não é menos certo que uma dama bonita pode muito bem amar os gregos e os seus presentes" (ASSIS, 1997, p. 39). Contudo, a sucessão narrativa confere dúvida à capacidade de imparcialidade do narrador defunto. Nem a morte oferece garantia de sabedoria ao narrador: "E depois eu confiava na minha boa Marcela; podia ter defeitos, mas amava-me..." (ASSIS, 1997, p. 39). Todavia, o leitor não tem certeza dessa dedução.

O narrador encerra o capítulo 18 com o projeto de se atirar ao oceano por Marcela, mais uma encenação dramática. O capítulo seguinte já compõe outra sequência, a da morte da mãe, com a preparação para esse tipo de experiência. $\mathrm{O}$ falecimento da mulher do capitão do navio e a atitude de Brás Cubas de manter-se longe, ainda que se tratasse de uma estranha, indicam que ele não estava pronto para enfrentar a morte. Logo, o projeto de se lançar ao mar por Marcela não se concretizaria, meras palavras retóricas, mais uma 
"ideia fixa" que não se solidifica. O capítulo 19, "A bordo", um dos mais belos do romance, inicia a sequência da morte materna, a de fato vivida por Brás Cubas e que o abala, infligindo marcas para sempre: "Mas esse duelo do ser e do não ser, a morte em ação, dolorida, contraída, convulsa, sem aparelho político ou filosófico, a morte de uma pessoa amada, essa foi a primeira vez que a pude encarar" (ASSIS, 1997, p. 49). O falecimento da mãe parece mostrar-lhe a figura feminina que realmente importa.

Experiências que desenvolvem outras facetas da personalidade de Brás Cubas. O narrador descreve Marcela sem defeitos, ao contrário de Virgília, cuja caracterização, no capítulo 27 , não poupa imperfeições, o que não representa menor afeto. $\mathrm{O}$ amor da maturidade permite enxergar os defeitos sem deixar de amar. Com essa postura, aproveita para criticar mais uma vez a idealização romântica: "Não digo que já lhe coubesse a primazia da beleza, entre as mocinhas do tempo, porque isto não é romance, em que o autor sobredoura a realidade e fecha os olhos às sardas e espinhas [...]" (ASSIS, 1997, p. 56).

Após a descrição de Virgília, o narrador indaga a si mesmo a respeito da capacidade de narrar os fatos exatamente como ocorreram e conclui: "Cada estação da vida é uma edição, que corrige a anterior, e que será corrigida também, até a edição definitiva, que o editor dá de graça aos vermes" (ASSIS, 1997, p. 57).

Essa "teoria das edições humanas" sintetiza o relativismo e é retomada quando Brás Cubas reencontra Marcela doente, decrépita e decadente. No capítulo 38, o ponto de vista não é mais o de um apaixonado, e sim o de quem já se sentiu ludibriado, desiludido e decepcionado por aquela mulher. Ao reencontrá-la, consegue finalmente ver o quanto era ambiciosa, mesmo quando a conheceu e se apaixonou. "O rosto dizia-me que não; ao mesmo tempo os olhos me contavam que, já outrora, como hoje, ardia neles a flama da cobiça. Os meus é que não souberam ver-lha; eram olhos da primeira edição" (ASSIS, 1997, p. 70).

Não se retorna no tempo para alterar os fatos, mas a interpretação acerca deles se modifica com o correr dos anos. Em Esaú e Jacó, também se define o tempo como transformador das percepções humanas: "o tempo é um rato roedor das cousas, que as diminui ou altera no sentido de lhes dar outro aspecto" (ASSIS, 2003, p. 35).

$\mathrm{O}$ relativismo ainda se faz presente na incerteza quanto à decadência financeira de Marcela. Alguns dizem que ela não perdeu tudo, mas esconde o dinheiro. O capítulo 39 traz curioso episódio com a visita de um vizinho à loja com uma menina de quatro anos que adora a "Santa Marcela". Afinal, em 
qual versão acreditar: na da mulher cuja existência se guia pela paixão do lucro ou na imagem infantil? O próprio Brás Cubas já oscilara entre o anjo e o demônio. Talvez isso demonstre o quanto o ser humano é complexo e contraditório, avesso a reducionismos de categorização. Consequentemente, Brás Cubas blasfema, ao longo da narrativa, a respeito das "ideias fixas" que almeja, mas sempre lhe escapam.

A crítica a essa incansável mania humana de classificação é constante na obra machadiana. Acreditar nas verdades absolutas e imutáveis implica certezas, tentativa de garantia de um mínimo de segurança, forma de proteção do homem. Contudo, não passa de grande ilusão a fim de evitar o temor do indefinível. A linguagem não apresenta capacidade de definição. Tantas sensações permanecem apenas como vivências incapazes de adquirir nomenclatura própria e sobre as quais as palavras transmitem parcas sombras. "Indefinível, não esqueças. E escabroso porque nada há pior que falar de sensações sem nome" (ASSIS, 2003, p. 106). Por isso se justifica a crítica ao excesso de descrições minuciosas das obras realistas, pois é mais cômodo detalhar objetos que as incertezas incompreensíveis de sentimentos e pensamentos humanos: "crede-me que eu preferia contar as rendas do roupão da moça, os cabelos apanhados atrás, os fios do tapete, as tábuas do teto e por fim os estalinhos da lamparina que vai morrendo... Seria enfadonho, mas entendia-se" (ASSIS, 2003, p. 106).

Essa visão sem condescendência da mulher também integra algumas crônicas intituladas somente pela data, que Machado de Assis escreveu para a Gazeta de Notícias, entre 1892 e 1897, na série "A Semana". A crônica, como gênero literário, aborda algum fato cotidiano, a fim de empreender olhar peculiar sobre assunto atual da época de publicação em tom de conversa com o leitor.

Nesse sentido, Machado destaca, na crônica de 17 de setembro de 1893, dois anúncios publicados no jornal de duas damas à procura de "protetores". A busca das jovens senhoras, Machado compara a fatos públicos: enquanto governantes se dividem, elas visam unir forças: "'Uma senhora séria precisa de um homem honesto que a proteja ocultamente; quem estiver nas condições' etc." (ASSIS, 2018c, p. 119). A outra é até mais direta: "'Uma moça distinta e bem-educada precisa de um cavalheiro rico que a proteja ocultamente; carta' etc." (ASSIS, 2018c, p. 119).

Em ambos os anúncios, ressalta o eufemismo quanto ao costume do século XIX explícito na relação entre verbo e advérbio contíguos: "proteger ocultamente". Machado expõe sem ressalvas a troca de mercadorias tipicamente capitalista, que invade os relacionamentos, os quais se 
convertem em meras transações naturalmente aceitas no comportamento social cotidiano: "Parece um ato de moças vadias, e é uma operação econômica" (ASSIS, 2018c, p. 119). Isso ocorre porque não há sentimentos envolvidos, mas trocas entre sexo e proteção financeira. Por isso, a análise machadiana restringe o "amor antigo" a "simples proteção" (ASSIS, 2018c, p. 119), em ato de domínio do homem e submissão da mulher, conforme exigência da sociedade patriarcal.

No entanto, o aspecto oculto que o advérbio impinge à situação revela a não exposição do protetor oficial. Por conseguinte, Machado distingue as duas anunciantes. A primeira almeja algo do mistério do amor ao solicitar "homem honesto", embora o cronista ironize a imagem da senhora: "uma necessitada do coração, e da vida" para quem "a casinha lhe basta" (ASSIS, 2018c, p. 120).

Enquanto a primeira poderia ir a pé à rua do Ouvidor, desde que o protetor lhe concedesse as botinas, que não precisariam ser "do Queiroz", provavelmente o dono de loja de calçados elegantes da época, a segunda exige "cavalheiro rico". Vestidos, brilhantes, carros, todo luxo feito para exibição pública de uma sociedade baseada na imagem e na riqueza, que alimentam os comentários nas ruas. Machado, então, elabora diálogos na crônica para reproduzir a hipocrisia e a aparência, que integram a convivência social. Ao ouvir o burburinho, o homem que a sustenta só poderia repetir internamente ser o responsável pela proteção para conservar o segredo.

Mais um anúncio de mulher consiste no tema de outra crônica, a de 17 de julho de 1892. Dessa vez, uma viúva "independente de meios" procura esposo "de meia-idade, sério, instruído, e também com meios de vida, que esteja como ela cansado de viver só [...]" (ASSIS, 2018a, p. 53, grifo do original). Embora não seja o homem procurado, o desejo de conhecer tal viúva toma conta do cronista, que afirma "tu não és qualquer pessoa, tu vales alguma coisa mais que o comum das mulheres" (ASSIS, 2018a, p. 53). Nem Marcelas, nem Virgílias. A franqueza do texto do anúncio demonstra o caráter de alguém que não pretende enganar ninguém, uma vez que deixa claro o cansaço da solidão. Ela não almeja amor, mas companhia, por isso a necessidade de instrução e idade compatíveis para ampliar chances de possíveis afinidades. Também não visa ser explorada nem sustentada por ninguém.

Como de hábito, Machado de Assis estabelece comparações com a cultura greco-latina e cita o remédio de Sêneca para o tédio, a solidão, como insuficiente para a viúva: "Tu já provaste esse preparado; não te fez nada. 
Tentas outro; mas queres menos um companheiro que uma companhia" (ASSIS, 2018a, p. 53). Amor implica companheirismo, porém para o combate ao tédio e à solidão basta companhia. A sinceridade do cronista converge com a personalidade da viúva, com maturidade para ouvir veemente conclusão. A crônica segue com supostos tópicos de fatos históricos e da época que poderiam constar nas conversas entre a mulher e o já encontrado esposo que atendesse às estipuladas condições.

Viúva independente de meios, todavia não independente emocionalmente. A vantagem pecuniária a diferencia das outras que dependem financeiramente de homens que se sentem proprietários por sustentá-las, como supõe o cronista ao imaginar a vontade do protetor de bradar a quem contempla a protegida nas ruas: "eu é que sou o dono e o autor" (ASSIS, 2018c, p. 121). No entanto, na obra de Machado, percebe-se não somente a mulher, mas qualquer indivíduo como objeto do homem.

O caráter da referida viúva, franca e independente financeiramente, contrasta com o das mulheres da primeira crônica citada e de Memórias póstumas de Brás Cubas. Estas confirmam as assertivas de outra crônica, a de 18 de dezembro de 1892, não sobre comportamento feminino, mas acerca de falsificação de café e até de chocolate: "dinheiro é mais forte que amor" e "É o amor da pecúnia" (ASSIS, 2018b, p. 76).

Nesse contexto, o ceticismo machadiano tinha razão de ser. Seja no romance ou na crônica, por meio das relações no âmbito público ou no privado, constata-se o dinheiro como o grande motor da sociedade, constituindo os relacionamentos de maneira ostensiva e revelando o verdadeiro caráter dos indivíduos. Poucos, como a viúva "independente de meios", conseguem manter a integridade nesse cínico cenário.

Em Memórias póstumas de Brás Cubas, esse papel se reserva a Eugênia. Pobre, bastarda e coxa, apaixonou-se pelo jovem Brás Cubas, mas foi devidamente desprezada por ele. A altivez de Eugênia, consciente da desigualdade social, sem súplicas e com olhar "de império" ante a hipocrisia de Cubas a dizer juras de amor, mesmo ao negar-lhe qualquer possibilidade de matrimônio, inverte a assimetria social em moral. O que Cubas denominou piedade não passava de covardia do rapaz fútil e preconceituoso, que nunca frustraria a expectativa social com uma mulher pobre e de defeito físico. Ao narrar o episódio, como todo escritor que imagina leitores hipotéticos, o defunto autor também presume algum dotado de "alma sensível", o qual lhe impinge a devida censura, que o obriga a racionalizar justificativa para se autodefender. Se no reencontro com Marcela, que antes gozara de luxo e beleza, o que lhe restou foram decrepitude e decadência, ao 
reencontrar-se com Eugênia, ela ainda o encara com dignidade, mesmo em um cortiço.

O contraste com valores morais se evidencia no meio onde predomina o disfarce para assumir importância no grande teatro social. A sociedade exibitória implica o cuidado com a aparência, pois "ao domínio da representação social se liga o medo da opinião pública" (LIMA, 1981, p. 70). Por isso, as tentativas frustradas de Brás Cubas na política e com o emplasto, por amor à glória pública, "sede de nomeada". Ou ainda a busca de "proteção" por parte de mulheres. Em sociedade fundamentada no dinheiro e na imagem, a ambiguidade da literatura de Machado de Assis obriga à leitura exigente, "graças à qual a normalidade e o senso das conveniências constituem apenas o disfarce de um universo mais complicado e por vezes turvo" (CANDIDO, 1995, p. 24). Dessa forma, consegue "estabelecer um contraste entre a normalidade social dos fatos e a sua anormalidade essencial" e sugerir "que o ato excepcional é normal, e anormal seria o ato corriqueiro" (CANDIDO, 1995, p. 27).

Desvencilhar-se das parcas opções oferecidas por esse esquema social exige ética e coragem, como a recusa de Flora em limitar-se a uma das alternativas representadas pelos irmãos Pedro e Paulo, de Esaú e Jacó. Como manter-se íntegro em sociedade antidemocrática, com o regime escravocrata ainda vigente, onde a normalidade consiste em mutilar o eu em prol da opinião alheia, depender de favores para a ascensão social, fomentar o homem como lobo do homem?

Aos dignos, miséria e solidão.

\section{Referências}

ASSIS, Machado de. Memórias póstumas de Brás Cubas. São Paulo: Globo, 1997. . Esaú e Jacó. São Paulo: Ática, 2003. . Dom Casmurro. São Paulo: Moderna, 1994.

. 17 de julho de 1892. In: PETRAGLIA, Benito; LIMA, Mariana da Silva; MELLO, Maria Elizabeth Chaves de (Orgs.). Opacam-se vidros: o olhar de Machado de Assis sobre o Brasil, em 50 crônicas da série "A Semana". Curitiba: CRV, 2018a. p. 53-55.

18 de dezembro de 1892. In: PETRAGLIA, Benito; LIMA, Mariana da Silva; MELLO, Maria Elizabeth Chaves de (Orgs.). Opacam-se vidros: o olhar de Machado de Assis sobre o Brasil, em 50 crônicas da série "A Semana". Curitiba: CRV, 2018b. p. 75-77. 
17 de setembro de 1893. In: PETRAGLIA, Benito; LIMA, Mariana da Silva; MELLO, Maria Elizabeth Chaves de (Orgs.). Opacam-se vidros: o olhar de Machado de Assis sobre o Brasil, em 50 crônicas da série "A Semana". Curitiba: CRV, 2018c. p. 119-121.

BOSI, Alfredo. Brás Cubas em três versões. Teresa - Revista de Literatura Brasileira, São Paulo, n. 6-7, p. 279-317, 2006.

CANDIDO, Antonio. Esquema de Machado de Assis. In: Vários escritos. 3. ed. São Paulo: Duas Cidades, 1995. p. 17-40.

LIMA, Luiz Costa. Sob a face de um bruxo. In: Dispersa demanda: ensaios sobre literatura e teoria. Rio de Janeiro: Francisco Alves, 1981. p. 57-123.

PETRAGLIA, Benito; LIMA, Mariana da Silva; MELLO, Maria Elizabeth Chaves de. Apresentação. In: (Orgs.). Opacam-se vidros: o olhar de Machado de Assis sobre o Brasil, em 50 crônicas da série "A Semana". Curitiba: CRV, 2018. p. 9-13.

ROBERTA DA COSTA DE SOUSA é Roberta da Costa de Sousa tem Doutorado e Mestrado em Teoria Literária pela UFRJ. Graduada em Comunicação Social (Jornalismo) na UFRJ e em Letras (Português-Literaturas) na Universidade do Estado do Rio de Janeiro (Uerj). Tem Especialização em Língua Portuguesa pelo Liceu Literário Português. http:// orcid.org/0000-0001-6496-4317. E-mail: professorarobertacs@gmail.com

Recebido: 14.03.2018 Aprovado: 15.05.2019 